or multiple regulators, up to the largest plants in use or contemplated.

Station Auxiliaries in their relation to the choice of exciter plant are discussed. The conclusion is reached that for large plants direct-connected individual exciters should be used, with emergency bus, and battery. The emergency bus should be supplied by one or more motor generators driven from the a-c. auxiliary bus supplying the other station auxiliaries. Thus the excitation is normally kept separate from the house plant or station auxiliary bus. The latter, supplied by a relatively large and efficient turbine forms a reliable supply for the station auxiliaries, with possibility of efficient heat balance in a steam plant and a reliable emergency supply for the excitation, unaffected by main bus disturbances.

\title{
Application of D-C. Generators to Exciter Service
}

\author{
BY C. A. BODDIE and F. L. MOON \\ Both of Engineering Dept., Westınghouse Electric \& Mfg. Co.
}

$\mathrm{T}^{\mathrm{H}}$ E purpose of the paper is to discuss some of the problems which arise in connection with the use of d-c. machines as exciters; such as choice, range and stability of exciter voltage ,stability of parallel operation, responsiveness, use of main rheostats, and use of compound field windings.

The choice of exciter voltage is usually not a matter of great importance; yet in some cases there are good engineering reasons for choosing 125 volts rather than 250 , or the reverse. When automatic regulators of the Tirrill type are used, the exciter must be capable of operating over a range from two to one to three to one; the maximum voltage required being 10 or 15 per cent above the rated value. If the exciter has considerable cumulative series field, it may be difficult to obtain the required minimum voltage.

Where automatic voltage regulators of the Tirrill type are employed, a responsive system is necessary to avoid hunting of the regulator; otherwise the regulator main control must be damped until the whole system is very sluggish. The responsiveness of the system depends chiefly upon the quickness with which the exciter voltage responds to changes in its field resistance and upon the speed with which the alternator field current responds to changes in the exciter voltage. The time rate of change of the voltage of a d-c. machine when its field resistance is altered, is proportional to the instantaneous difference between the $I R$ drop in the field circuit, and the terminal voltage of the machine, that is, the "opening" between the magnetization curve and the volt-ampere characteristic of the shunt field circuit, as measured in volts: and is inversely proportional to the interlinkages of flux and field turns at rated voltage. A number of secondary factors have an influence upon the final result.

The problem of running exciters in parallel is largely the same as with other d-c. machines. Where Tirrill type regulators are used, the situation is more complicated owing to the range of voltage over which the

\footnotetext{
Abstract of paper to be presented at the A.I.E.E. Annual Convention, June 29-July 2, 1920. Advance copies of the complete paper can be obtained as soon as available by applying to Institute headquarters.
}

machines must operate. There are several ways in which the drooping characteristic necessary for stable parallel operation may be obtained; and in general it may be said that in any case exciters may be made to parallel satisfactorily. Further, when automatic voltage regulation is used approximately correct load division at all voltages is ensured by making the maximum voltages the same, and making the average rate of decay of voltage about the same as the average of building up for each exciter.

Differential series windings are not detrimental to regulator performance and in some cases may be of benefit in promoting stability of parallel operation. Cumulative series windings, if they constitute a considerable portion of the total field strength may seriously impair the quality of regulation obtained. In some cases trouble from polarity reversal of compound-wound machines under abnormal conditions, has been experienced. Sufficient cumulative series to balance the demagnetizing armature reaction in a noncommutating pole machine, is not only harmless but is desirable; and is very necessary where broad range regulating is used, in order to avoid polarity reversal.

When the exciters are connected to a common bus the excitation voltage cannot be varied to suit the needs of an individual generator; and a field rheostat or equivalent device is needed. When individual exciters are used, the excitation may be controlled by adjusting the exciter field rheostat, or by means of main field rheostat or equivalent. When it is considered safe to rely entirely upon automatic voltage control, the main rheostat may be omitted entirely or reduced to a small affair. Where thoroughly dependable hand control is desired, the question of exciter voltage stability must be considered. At the lower exciting voltages, rather poor control over the exciter voltage is experienced; hence it would be desirable to have some variable resistance in the main field circuit to render unnecessary the operation of the exciter upon the straight part of its magnetization curve.

One of the two fundamental ways of improving the response of an exciter is to increase the "opening" between the magnetization curve and the volt-ampere 
characteristic of the shunt field circuit, though the possible gain is quite limited for several reasons. The other way is to reduce the number of interlinkages at rated voltage. As this depends partly upon the magnetic flux, some gain may be made by a reduction in the value of the flux. However the principal gain comes from a reduction in the number of turns; as this means a corresponding increase in the field current, the latter may require attention. The current which the shunting relay contacts can handle is limited in value, the limit lying between 20 and 25 amperes unless the block of resistance shunted by the contacts is abnormally small. If the needed reduction in the number of turns makes the field current too high, which is liable to happen if the exciter is built on a relatively large frame, the current must be split up among two or more circuits, as by winding the coils with several conductors in parallel, or by series parallel connection of the field coils.

The method of driving exciters by connecting them directly to the main units, has a definite relation to exciter design. On account of their disproportionate cost, direct-connected exciters are not often used with low-speed, small capacity units; and on account of the difficulty of building satisfactory d-c. machines for very high speeds, they are not often used with highspeed turbo-generators. For low-speed, large capacity units the exciters, if direct-connected, must be built on a relatively large frame, as a result of which they are inherently sluggish. However, they can be made very satisfactory from the voltage regulator standpoint by some of the methods mentioned above.

\title{
Exciter Practise in the Northwest
}

\author{
BY J. D. ROSS \\ Supt. of Lightıng, Member Board of Public Works, Seattle, Wash.
}

$\mathbf{E}^{\mathrm{x}}$ XCITER practise in existing Pacific Coast plants is indicated in a table giving the number and size of generators, the number and size of exciters with their drive, the manner of connection and whether a regulator is used or not, for the largest or newest hydroelectric plant of each large power company in British Columbia, Washington, Oregon and California.

Because of the difference in size and characteristics of machines whose fields are fed from the same exciter bus, and because of its complication and its tendency to pile up the voltage on a short circuit, the automatic regulator is little used in Northwestern plants.

For a new 15,000-kw. hydroelectric unit being added to the Cedar Falls station of the Seattle system, the writer chose an exciter large enough for a 36,000-kw. plant, the full final development of the entire station, so that only one exciter will be operating at a time. This design was preferred to that of an individual exciter for each generator, because of its greater simplicity especially since a regulator is to be used. The idea of simplicty is further emphasized in this plant by making the new generator and its transformer a unit, without intermediate busbars, using mica insulation, class $B$, throughout in both generator and transformer.

Auxiliaries are driven from an auxiliary bus energized by a prime mover and a battery, and entirely separate from the exciters, assuring a steady voltage for auxiliaries and removing a complication from the exciter system.

Abstract of paper to be presented at the A. I. E. E. Annual Convention, June 29-July 2, 1920. Advance copies of the complete paper can be obtained as soon as available by applying to Institute headquarters.
The same plan of excitation is followed in the new $15,000-\mathrm{kw}$. unit being added to the steam plant in Seattle, where $35,000-\mathrm{kw}$. three-unit plant will be controlled through one exciter, steam turbine and motordriven. In order to get a large enough exciter of the proper speed, one exciter generator is mounted on each end of a shaft, with exciter turbine and motor between. In the new steam unit also the generator and transformers are connected together directly, without intermediate buses.

The writer sees no logical excuse for the compoundwound exciter; it tends to pile up the voltage on a short circuit, and to give much trouble in paralleling. The shunt wound machine with ample voltage range is ideal.

The trend on the Coast is away from small generators of different characteristics to large and uniform generating units. A number of plants are using combined waterwheel and induction-motor drive for at least one of the exciters. One company uses an exciter on each main unit shaft, each exciter large enough to supply two generators, with no added spare exciter. Another company uses the same plan but adds a spare exciter unit, driven by a motor.

The ideal exciter system for an entirely new plant is one in which each generator has its own shunt-wound exciter, driven by prime mover and having its own regulator. This allows a new generator to be ordered with its proper exciter regardless of changes in design of machines. In adding a machine to an old plant having its exciters connected to a bus, the use of one large exciter to operate the entire plant is the best compromise. The old exciters may then be used as duplicates. 